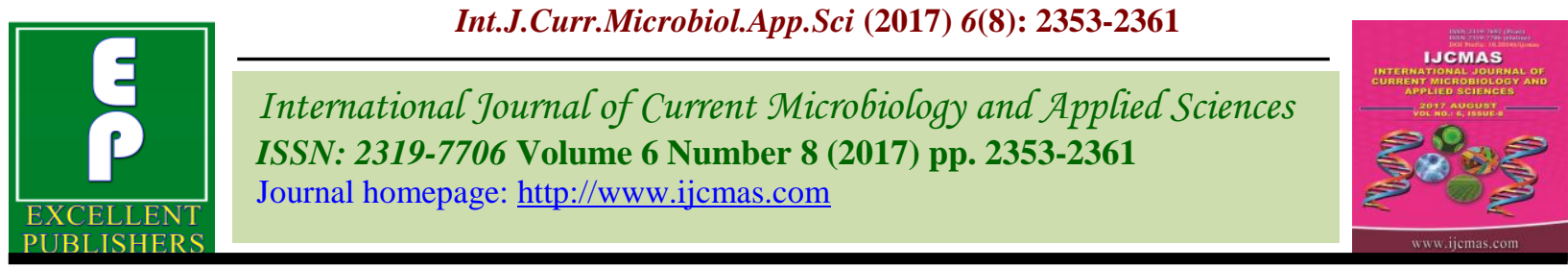

Original Research Article https://doi.org/10.20546/ijcmas.2017.608.278

\title{
RAPD Based Genetic Diversity Analysis in 25 Genotypes of Withania somnifera (L.) Dunal
}

\author{
Surya Chauhan*, Arunabh Joshi and Devendra Jain \\ Department of Molecular Biology and Biotechnology, Rajasthan College of Agriculture, \\ Maharana Pratap University of Agriculture and Technology, Udaipur 31300, (Rajasthan), India \\ *Corresponding author
}

\begin{tabular}{l} 
Ke y w o r d s \\
RAPD, Genetic \\
diversity, \\
25 genotypes. \\
Article Info \\
$\begin{array}{l}\text { Accepted: } \\
21 \text { June } 2017 \\
\text { Available Online: } \\
10 \text { August } 2017\end{array}$ \\
\hline
\end{tabular}

A B S T R A C T
Genetic diversity was evaluated among 25 genotypes of Withania somnifera L. Dunal using RAPD marker. The 15 RAPD primers screened amplified 150 bands among which 141 bands (94\%) were polymorphic. The Polymorphic Information Content (PIC) values ranged from 0.162 (OPA-05) to 0.422 (OPA-02) with an average of 0.310 . A total of five primers detected in the study produced seven unique bands in seven genotypes Jaccards similarity coefficient values ranged from 0.29 to 0.85 with an average of 0.57 . Cluster analysis based on Jaccards similarity coefficient using Un-weighted Pair Group Method with Arithmetic Averages (UPGMA) grouped all the 25 genotypes into two major groups. The cluster I is a major cluster consisting of 20 genotypes whereas cluster II which is minor consists of 5 genotypes. The results show that the level of genetic variation was high among the Ashwagandha genotypes.

\section{Introduction}

Ashwagandha $($ Fam $=$ Solanaceae $)[($ ashwa $=$ horse) and (gandha = smell), "horse like smell"], one of the most important medicinal plant also known as Withania somnifera $\mathrm{L}$. Dunal, poison gooseberry, winter cherry and Indian ginseng (parallel to Panax Ginseng, of Chinese origin) (Tripathi et al., 1996; Singh et al., 1998). Due to its medicinal properties, it had been used since ancient times as "rasayana" and "medha rasayana" in Ayurveda (CSIR, 1976) and now-a-day paving pathway for preparing allopathy drugs. C-28 steroidal lactones known as with anolides are mainly responsible for vast medicinal properties such as anti- inflammatory, anticonvulsive, antitumor, immunosuppressive, antioxidant and adaptogenic action. The main part of plant which contributes for these with anolides and alkaloids are roots and leaves.

It is widely distributed from the Southern Mediterranean region to the Canary Islands and to South and East Africa; from Palestine up to North India, covering Israel, Jordan, Egypt, Sudan, Iran, Afghanistan, Baluchistan and Pakistan. It is widely distributed throughout the drier and subtropical parts of India. In India, it grows wildly/extensively in Madhya Pradesh, Uttar Pradesh, Andhra 
Pradesh, Gujarat, Maharashtra, Rajasthan and Punjab extending to the mountainous regions of Himachal Pradesh and Jammu.

Molecular marker technique is a powerful tool for evaluating genetic variation and exploring evolutionary relationships among and within plant species (Hoisington et al., 1998; Stuber, 1995). PCR (Polymerase Chain Reaction)-based markers i.e. RAPD are being used in the analysis of genetic diversity in crop plants because of their relative ease. There is no need of prior knowledge about the genome, which makes RAPD a common method for such studies in different plants. The RAPD technique (Williams et al., 1990) is faster and cheaper for revealing genetic polymorphism. RAPD markers have been widely used for evaluating genetic variation and genetic relationships, genetic mapping, identifying genotypes, etc., with various plants.

RAPD markers have been used for genetic diversity analysis in ashwagandha by many workers (Arif et al., 2010; Dharmar et al., 2011; Mir et al., 2011; Bhat et al., 2012; Khatak et al., 2013; Sairkar et al., 2013; Udaykumar et al., 2013; Khanna et al., 2014; Khan and Shah, 2016; Tiwari and Shrivastava, 2016).

The objective of this work was to evaluate the extent and distribution of genetic diversity among 25 accessions of Withania somnifera using RAPD markers and to determine the phylogenetic relationship amongst them with the future goal of assisting the marker assisted crop improvement programme.

\section{Materials and Methods}

In the present investigation, seed of 25 diverse genotypes of Withania somnifera Dunal were procured from AICRP on MAP\&B (Medicinal and Aromatic Plant and
Betelvine). Source details of the genotypes used are given in table 1. Young fresh and healthy leaves were collected and DNA extraction was done following the cetyl trimethyl ammonium bromide (CTAB) method (Doyle and Doyle, 1990).The extracted genomic DNA was analysed on $0.8 \%$ agarose gel and was diluted to an optimum concentration using TE for polymerase chain reaction (PCR). A total of 20 arbitrary decamer primers were initially used, out of which 15 primers showed clear, scorable and highly polymorphic bands (Table 2).

For RAPD analysis, the genomic DNA was amplified in a reaction volume of $20 \mathrm{ml}$ containing $50 \mathrm{ng}$ of template DNA,1x reaction buffer, 1 unit of Taq DNA polymerase, $200 \mathrm{mM}$ each of dNTPs mix and $0.5 \mu \mathrm{M} /$ reaction of primer using a programmable thermo-cycler DNA Engine (Biorad, Germany) with the following cycling parameters: initial denaturation at $94{ }^{\circ} \mathrm{C}$ for 4 min, followed by 44 cycles of denaturation at $94{ }^{\circ} \mathrm{C}$ for $45 \mathrm{sec}$, annealing at $32{ }^{\circ} \mathrm{C}$ for 2 min, and extension at $72{ }^{\circ} \mathrm{C}$ for $2 \mathrm{~min}$. A final extension was done for $10 \mathrm{~min}$ at $72{ }^{\circ} \mathrm{C}$ with a hold temperature of $4{ }^{\circ} \mathrm{C}$. The amplified PCR products were electrophoretically separated on $1.2 \%$ agarose gel prepared in $1 \mathrm{x}$ TAE buffer containing ethidium bromide (EtBr) staining dye. The gel was run for $3 \mathrm{~h}$ at $50 \mathrm{~V}$.The size of the amplified DNA fragments were determined using low base pair and 500bp DNA ladders= (Bangalore Genie, India) as standard molecular size markers. DNA fragments were visualized under UV-trans-illuminator and photographed using gel documentation system. Scoring of amplicons obtained from different RAPD markers was done on the basis of presence (taken as 1) or absence (taken as 0) of bands for each primer. For banding pattern only clear and unambiguous bands were scored for each primer. Comparison of band position 
was done relative to molecular weight of standard DNA ladders. Accordingly, a rectangular binary data matrix was obtained and statistical cluster analysis was performed using the NTSYS-pc version 2.02e (Rohlf, 1998). A pair wise similarity matrix was generated and the cluster analysis was performed via unweighted pair group method with arithmetic averages (UPGMA) to develop a dendrogram. A two-dimensional and three-dimensional principal component analysis (PCA) was constructed to provide another means of testing the relationship among the genotypes.

\section{Results and Discussion}

Among the 20 RAPD primers used for initial screening, 15 markers produced polymorphic, reproducible and scorable bands. A total of 150 bands were generated from 15 RAPD primers, of which 141 bands were polymorphic (94\%) with an average of 12 polymorphic bands per primer (Table 2). The total number of amplified bands varied between 6 (primer OPA-02 and OPA-06) and 18 (primer OPB-05). The overall size of PCR amplified products ranged between $100 \mathrm{bp}$ to $3000 \mathrm{bp}$. The percent polymorphism ranged from as low as 50 (OPA-02) to as high as 100 (C-19, OPA03, OPA06, OPB4, OPB05, OPB06, OPB07, OPC 05, P-20 and S-34).The average PIC was 0.310 ranging from 0.164 to 0.422 . The lowest and the highest PIC value were recorded for primer OPA-05 and OPA02 respectively. Figure 1 shows the amplification pattern obtained from primer OPA-05 produced 9 polymorphic bands.

7 unique bands (band which is present in a particular genotype but absent in rest of the genotypes) were detected in 6 genotypes viz., AWS2B, UWS 56, UWS 59, UWS 32, UWS 37 and UWS 22 with 5 RAPD primers (OPA05 OPB-04, OPB-05, OPC-05 and S-34). The genotype UWS 32 gave maximum number of distinct bands i.e., 2. The sizes of these unique bands ranged from 350 to $3000 \mathrm{bp}$ (Table 3).

Based on RAPD similarity matrix data, the values of similarity coefficient ranged from 0.29 to 0.85 i.e., $29-85 \%$ or genetic diversity ranged from 15 to $71 \%$. The average similarity across all the genotypes was found out to be 0.57 showing that the genotypes were moderately diverse. Maximum similarity value of 0.85 was observed between genotypes UWS 23 and UWS 28 followed with a similarity coefficient value of 0.78 between UWS 11 and UWS 13. Similarly, minimum similarity value of 0.29 was observed between genotypes UWS 10 and UWS 67 and between UWS 10 and UWS 77 followed by a similarity coefficient of 0.3 between UWS 67 and UWS 15 (Table 4).

The RAPD cluster tree analysis of $25 W$. somnifera L. Dunal genotypes showed that they could be mainly divided into 2 clusters at a similarity coefficient of 0.43 and 0.61 respectively (Fig. 2). The Cluster I is a major cluster including 20 genotypes and it can be divided into 2 sub-clusters i.e. sub cluster I and II at 0.54 and 0.49 similarity coefficients respectively. Sub cluster I can be further divided into 2 groups, subgroup A and B at 0.74 and 0.76 similarity coefficients.

Subgroups A and B includes 4 genotypes viz., JA-134, JA-20, RVA 100 and HWS-8-14 from which JA-20 and JA-134 are related to each other whereas HWS-8-14 and RVA 100 are related to each other. Subgroup C and D at 0.68 and 0.73 similarity coefficient includes 5 genotypes viz., AWS2B, UWS 134, UWS 111, UWS 98 and UWS 93.From these genotypes, UWS 134 and UWS 111 are related to each other. Similarly, UWS 98 and UWS 93 are related to each other at 0.73 similarity coefficient value. AWS2B is out grouped at 0.69 similarity coefficient. 
Fig.1 RAPD profile of $W$. somnifera L. Dunal generated through OPA-05 primer

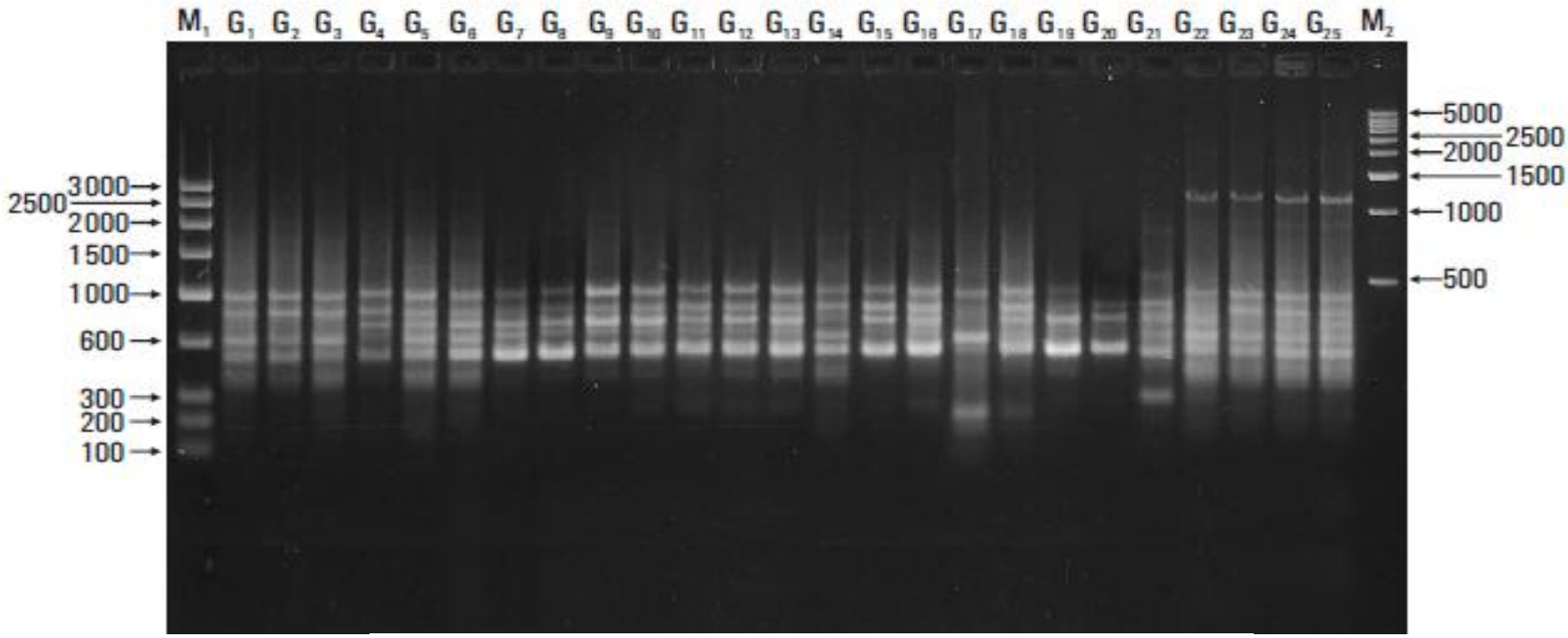

RAPD profile generated through OPA-05 (5'AGGGGTCTTG'3)

$\mathrm{M}_{1}=$ Low Base Pair Range DNA ladder; $\quad \mathrm{M}_{2}=\mathbf{5 0 0}$ bp DNA Ladder

G1-G25 represents following W.somnifera L. Dunal genotypes:

$\begin{array}{lllll}\text { G1: UWS 10, } & \text { G2: UWS 11, } & \text { G3: UWS 13, } & \text { G4: UWS 15, } & \text { G5: UWS 22, } \\ \text { G6: UWS 23, } & \text { G7:UWS 22, } & \text { G8:UWS 23, } & \text { G9:UWS 28, } & \text { G10:UWS 32, } \\ \text { G11:UWS 35, } & \text { G12:UWS 37, } & \text { G13:UWS 56, } & \text { G14:UWS 59, } & \text { G15:UWS 60, } \\ \text { G16:UWS 67, } & \text { G17:UWS 92, } & \text { G18:UWS 93, } & \text { G19:UWS 98, } & \text { G20:UWS 11, } \\ \text { G21:UWS 134, } & \text { G22:AWS2B, } & \text { G23:HWS-8-14, } & \text { G24:RVA 100 } & \text { G25: JA-20 }\end{array}$

Fig.2 Dendrogram constructed with UPGMA clustering method of 25 genotype of $W$. somnifera L. Dunal Using RAPD Primers

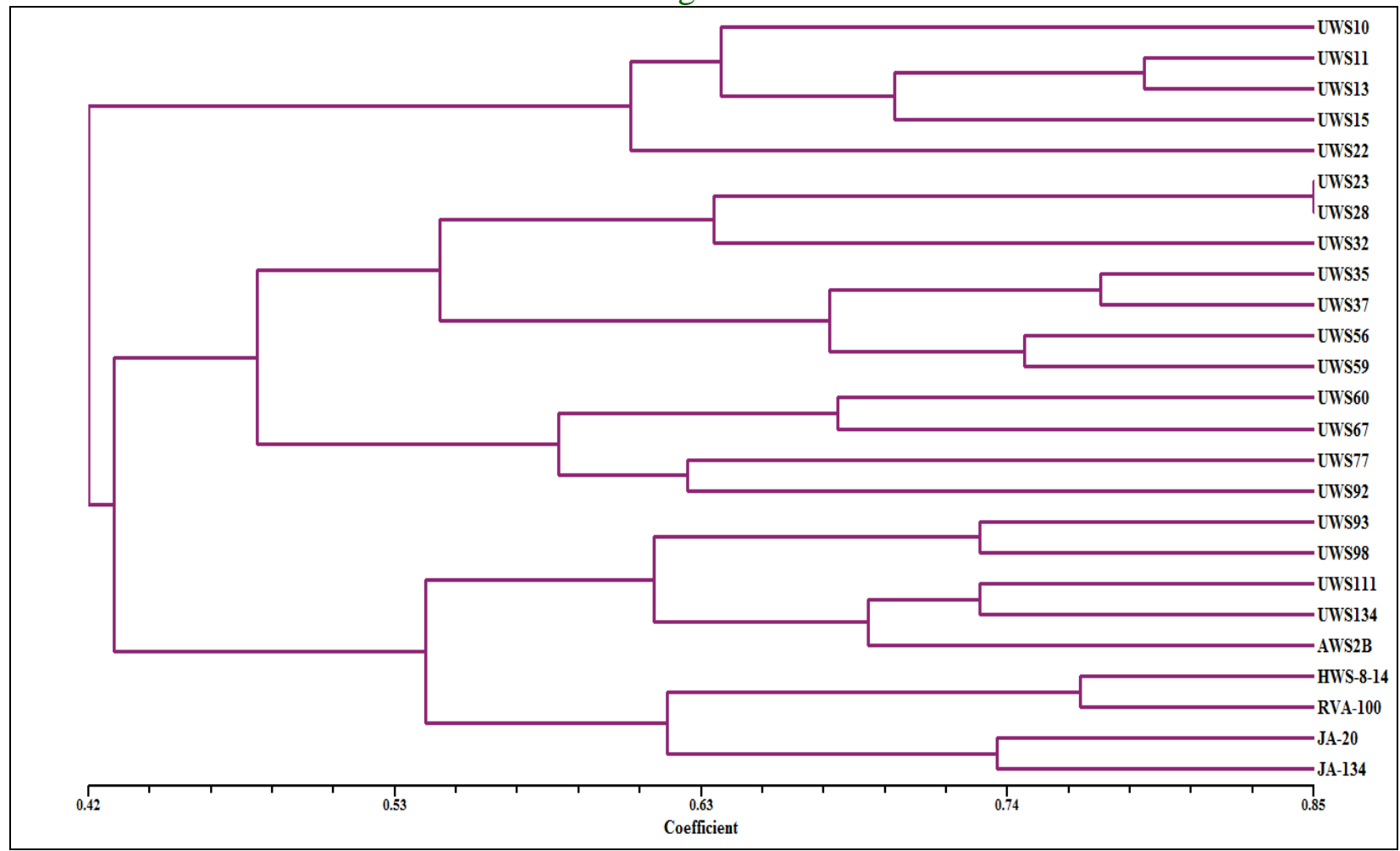


Fig.3 Two dimensional and three dimensional PCA (Principal Component Analysis) scaling of 25 genotypes of $W$. somnifera L. Dunal using RAPD markers
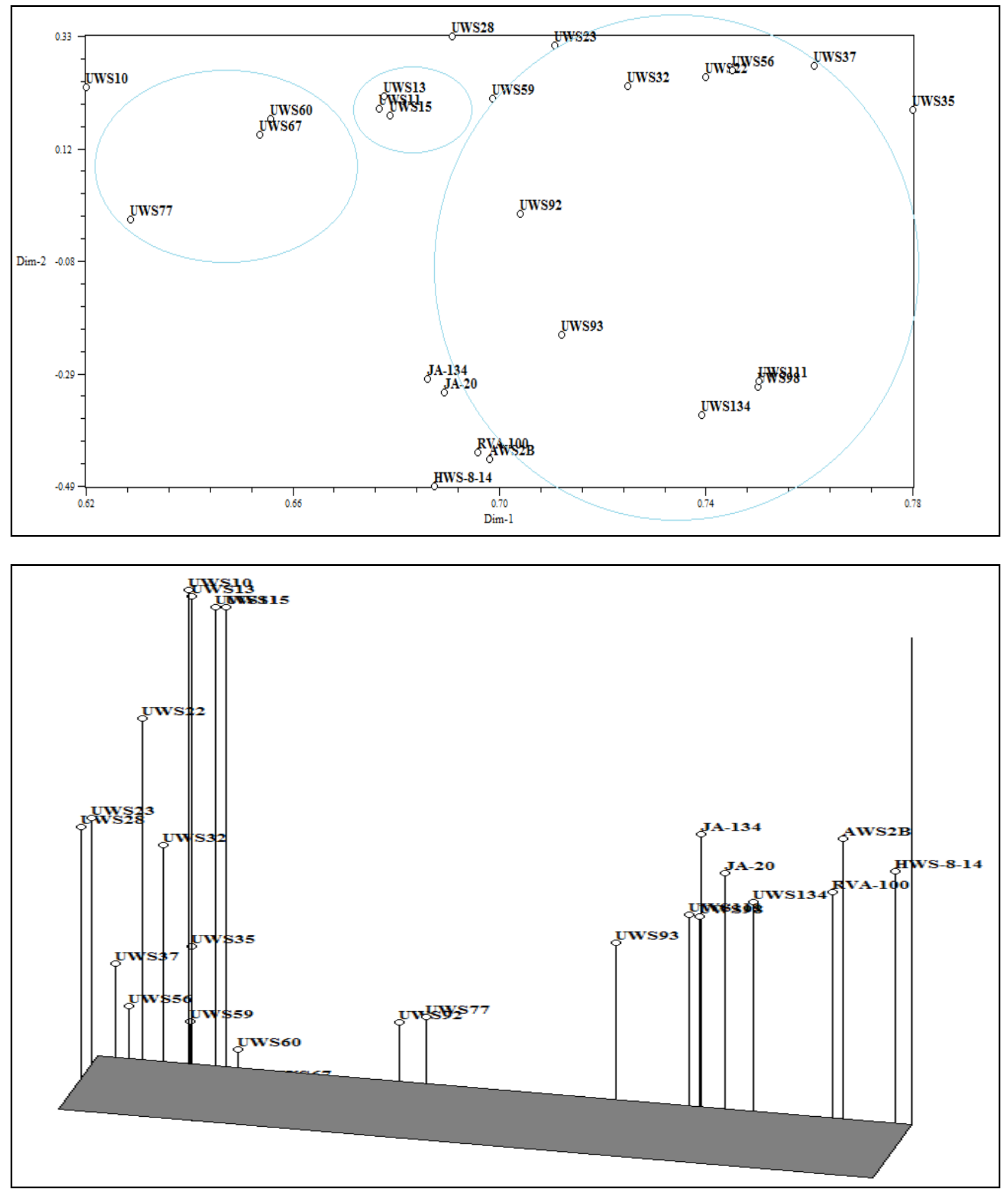
Table.1 Details of Twenty five genotypes of Ashwagandha used in present investigation

\begin{tabular}{|c|c|}
\hline Genotypes & Source \\
\hline UWS-10 & Germplasm Collection AICRP in MAP\&B, Udaipur \\
\hline UWS-11 & -do- \\
\hline UWS-13 & - do- \\
\hline UWS-15 & -do- \\
\hline UWS-22 & -do- \\
\hline UWS-23 & -do- \\
\hline UWS-28 & -do- \\
\hline UWS-32 & -do- \\
\hline UWS-35 & - do- \\
\hline UWS-37 & - do- \\
\hline UWS-56 & - do- \\
\hline UWS-59 & - do- \\
\hline UWS-60 & - do- \\
\hline UWS-67 & -do- \\
\hline UWS-77 & - do- \\
\hline UWS-92 & - do- \\
\hline UWS-93 & - do- \\
\hline UWS-98 & - do- \\
\hline UWS-111 & - do- \\
\hline UWS-134 & - do- \\
\hline AWS2B & AAU, Anand \\
\hline HWS-08-14 & CCSHAU, Hisar \\
\hline RVA-100 & RVSKVV, Mandsaur \\
\hline JA-20 & -do- \\
\hline JA-134 & -do- \\
\hline
\end{tabular}

Table.2 DNA amplification profile and polymorphism generated in W. somnifera L. Dunal using 15 RAPD primers

\begin{tabular}{|c|c|c|c|c|c|c|}
\hline S. No. & Primer & \multirow{2}{*}{$\begin{array}{l}\text { Molecular } \\
\text { weight range } \\
\end{array}$} & & \multirow{2}{*}{$\begin{array}{l}\text { Total no. of } \\
\text { bands } \\
\text { amplified (x) }\end{array}$} & & \multicolumn{2}{l}{ Polymorphic bands } & \multirow{2}{*}{ PIC* } \\
\cline { 5 - 6 } & & Number & Frequency (\%) & \\
\hline 1. & C-19 & $2500-200$ & 10 & 10 & 100 & 0.393 \\
\hline 2. & OPA-02 & $1400-300$ & 6 & 3 & 50 & 0.181 \\
\hline 3. & OPA-03 & $2500-100$ & 12 & 12 & 100 & 0.372 \\
\hline 4. & OPA-05 & $3000-200$ & 11 & 9 & 81.8 & 0.164 \\
\hline 5. & OPA-06 & $2000-250$ & 6 & 6 & 100 & 0.279 \\
\hline 6. & OPA-07 & $2100-250$ & 10 & 9 & 90 & 0.265 \\
\hline 7. & OPA-08 & $2100-400$ & 9 & 8 & 90 & 0.298 \\
\hline 8. & OPB-01 & $2100-400$ & 7 & 5 & 71.4 & 0.258 \\
\hline 9. & OPB-04 & $3000-350$ & 11 & 11 & 100 & 0.32 \\
\hline 10. & OPB-05 & $2500-100$ & 20 & 20 & 100 & 0.310 \\
\hline 11. & OPB-06 & $2500-200$ & 10 & 10 & 100 & 0.392 \\
\hline 12. & OPB-07 & $2600-300$ & 10 & 10 & 100 & 0.343 \\
\hline 13. & OPC-05 & $3000-200$ & 10 & 10 & 100 & 0.305 \\
\hline 14. & P-20 & $2100-200$ & 10 & 10 & 100 & 0.345 \\
\hline 15. & S-34 & $2400-100$ & 8 & 8 & 100 & 0.422 \\
\hline & Total & & $\mathbf{1 5 0}$ & $\mathbf{1 4 1}$ & $\mathbf{9 2 . 2 1}$ & $\mathbf{0 . 3 1 0}$ \\
\hline
\end{tabular}

*Polymorphic Information Content, * Operon series code

Table.3 Genotype specific band as detected by 5 RAPD primers as shown by 4 different genotypes of W. somnifera L. Dunal

\begin{tabular}{|c|c|c|c|c|}
\hline S. No. & Primer code & Total no. of unique bands & Genotype & Size of bands (bp) \\
\hline 1. & OPA-05 & 1 & AWS2B & 2000 \\
\hline & & 2 & UWS 56 & 1200 \\
\hline. & OPB-04 & 1 & UWS 59 & UWS 32 \\
\hline 3. & OPB-05 & 2 & UWS 32 & 2400 \\
\hline 4. & OPC-05 & 1 & UWS 37 & 25000 \\
\hline 5. & S-34 UWS 22 & 1500 \\
\hline Total & \multicolumn{4}{|c|}{} \\
\hline
\end{tabular}


Table.4 Jaccards similarity coefficient for RAPD profile generated by Agarose gel electrophoresis

\begin{tabular}{|c|c|c|c|c|c|c|c|c|c|c|c|c|c|c|c|c|c|c|c|c|c|c|c|c|c|}
\hline $\begin{array}{l}\text { Genotyp } \\
\text { es }\end{array}$ & $\begin{array}{l}\text { UWS } \\
10\end{array}$ & $\begin{array}{l}\text { UW } \\
\text { S } 11\end{array}$ & $\begin{array}{l}\text { UW } \\
\text { S } 13\end{array}$ & $\begin{array}{l}\text { UW } \\
\text { S } 15\end{array}$ & $\begin{array}{l}\text { UWS } \\
22\end{array}$ & $\begin{array}{l}\text { UWS } \\
23\end{array}$ & $\begin{array}{l}\text { UW } \\
\text { S } 28\end{array}$ & $\begin{array}{l}\text { UW } \\
\text { S 32 }\end{array}$ & $\begin{array}{l}\text { UW } \\
\text { S } 35\end{array}$ & $\begin{array}{l}\text { UW } \\
\text { S } 37\end{array}$ & $\begin{array}{l}\text { UW } \\
\text { S } 56\end{array}$ & $\begin{array}{l}\text { UW } \\
\text { S } 59\end{array}$ & $\begin{array}{l}\text { UW } \\
\text { S } 60\end{array}$ & $\begin{array}{l}\text { UW } \\
\text { S } 67\end{array}$ & $\begin{array}{l}\text { UW } \\
\text { S } 77\end{array}$ & $\begin{array}{l}\text { UWS } \\
92\end{array}$ & $\begin{array}{l}\text { UW } \\
\text { S } 93\end{array}$ & $\begin{array}{l}\text { UW } \\
\text { S } 98\end{array}$ & $\begin{array}{l}\text { UWS } \\
111\end{array}$ & $\begin{array}{l}\text { UWS } \\
134\end{array}$ & $\begin{array}{l}\text { AWS } \\
\text { 2B }\end{array}$ & $\begin{array}{l}\text { HWS } \\
-8-14\end{array}$ & $\begin{array}{l}\text { RVA- } \\
100\end{array}$ & $\begin{array}{l}\text { JA- } \\
20\end{array}$ & $\begin{array}{l}\text { JA- } \\
134\end{array}$ \\
\hline UWS 10 & 1.00 & & & & & & & & & & & & & & & & & & & & & & & & \\
\hline UWS 11 & 0.71 & 1.00 & & & & & & & & & & & & & & & & & & & & & & & \\
\hline UWS 13 & 0.64 & 0.78 & 1.00 & & & & & & & & & & & & & & & & & & & & & & \\
\hline UWS 15 & 0.56 & 0.64 & 0.76 & 1.00 & & & & & & & & & & & & & & & & & & & & & \\
\hline UWS 22 & 0.58 & 0.56 & 0.6 & 0.68 & 1.00 & & & & & & & & & & & & & & & & & & & & \\
\hline UWS 23 & 0.43 & 0.47 & 0.48 & 0.51 & 0.62 & 1.00 & & & & & & & & & & & & & & & & & & & \\
\hline UWS28 & 0.42 & 0.45 & 0.44 & 0.46 & 0.58 & 0.85 & 1.00 & & & & & & & & & & & & & & & & & & \\
\hline UWS 32 & 0.46 & 0.45 & 0.45 & 0.48 & 0.59 & 0.63 & 0.65 & 1.00 & & & & & & & & & & & & & & & & & \\
\hline UWS 35 & 0.46 & 0.45 & 0.43 & 0.47 & 0.6 & 0.53 & 0.57 & 0.7 & 1.00 & & & & & & & & & & & & & & & & \\
\hline UWS 37 & 0.46 & 0.44 & 0.43 & 0.44 & 0.6 & 0.53 & 0.53 & 0.63 & 0.77 & 1.00 & & & & & & & & & & & & & & & \\
\hline UWS 56 & 0.38 & 0.42 & 0.42 & 0.43 & 0.52 & 0.53 & 0.53 & 0.55 & 0.7 & 0.77 & 1.00 & & & & & & & & & & & & & & \\
\hline UWS 59 & 0.34 & 0.4 & 0.4 & 0.38 & 0.44 & 0.44 & 0.44 & 0.51 & 0.61 & 0.64 & 0.75 & 1.00 & & & & & & & & & & & & & \\
\hline UWS 60 & 0.33 & 0.39 & 0.38 & 0.32 & 0.38 & 0.44 & 0.41 & 0.39 & 0.47 & 0.55 & 0.58 & 0.66 & 1.00 & & & & & & & & & & & & \\
\hline UWS 67 & 0.29 & 0.32 & 0.33 & 0.3 & 0.39 & 0.43 & 0.42 & 0.43 & 0.51 & 0.53 & 0.57 & 0.6 & 0.68 & 1.00 & & & & & & & & & & & \\
\hline UWS 77 & 0.29 & 0.33 & 0.33 & 0.33 & 0.37 & 0.42 & 0.4 & 0.37 & 0.44 & 0.46 & 0.43 & 0.43 & 0.57 & 0.57 & 1.00 & & & & & & & & & & \\
\hline UWS 92 & 0.33 & 0.39 & 0.4 & 0.38 & 0.42 & 0.48 & 0.47 & 0.44 & 0.51 & 0.51 & 0.52 & 0.47 & 0.56 & 0.63 & 0.63 & 1.00 & & & & & & & & & \\
\hline UWS 93 & 0.36 & 0.4 & 0.42 & 0.41 & 0.46 & 0.41 & 0.41 & 0.44 & 0.5 & 0.43 & 0.48 & 0.47 & 0.44 & 0.48 & 0.48 & 0.53 & 1.00 & & & & & & & & \\
\hline UWS 98 & 0.39 & 0.45 & 0.46 & 0.47 & 0.46 & 0.4 & 0.41 & 0.44 & 0.53 & 0.46 & 0.47 & 0.45 & 0.41 & 0.46 & 0.46 & 0.54 & 0.73 & 1.00 & & & & & & & \\
\hline $\begin{array}{l}\text { UWS } \\
111\end{array}$ & 0.36 & 0.43 & 0.45 & 0.44 & 0.48 & 0.44 & 0.43 & 0.49 & 0.55 & 0.48 & 0.49 & 0.44 & 0.39 & 0.45 & 0.43 & 0.52 & 0.62 & 0.7 & 1.00 & & & & & & \\
\hline $\begin{array}{l}\text { UWS } \\
134\end{array}$ & 0.41 & 0.43 & 0.4 & 0.41 & 0.47 & 0.42 & 0.4 & 0.48 & 0.53 & 0.48 & 0.44 & 0.42 & 0.39 & 0.41 & 0.43 & 0.53 & 0.57 & 0.64 & 0.73 & 1.00 & & & & & \\
\hline AWS2B & 0.39 & 0.46 & 0.41 & 0.44 & 0.42 & 0.37 & 0.36 & 0.42 & 0.47 & 0.41 & 0.4 & 0.37 & 0.33 & 0.32 & 0.38 & 0.41 & 0.53 & 0.64 & 0.65 & 0.73 & 1.00 & & & & \\
\hline $\begin{array}{l}\text { HWS-8- } \\
14\end{array}$ & 0.34 & 0.38 & 0.35 & 0.39 & 0.41 & 0.38 & 0.36 & 0.45 & 0.44 & 0.41 & 0.38 & 0.37 & 0.34 & 0.34 & 0.38 & 0.43 & 0.49 & 0.55 & 0.58 & 0.65 & 0.69 & 1.00 & & & \\
\hline $\begin{array}{l}\text { RVA- } \\
100\end{array}$ & 0.33 & 0.37 & 0.37 & 0.37 & 0.41 & 0.44 & 0.43 & 0.44 & 0.45 & 0.4 & 0.41 & 0.41 & 0.39 & 0.35 & 0.4 & 0.42 & 0.52 & 0.55 & 0.58 & 0.55 & 0.58 & 0.77 & 1.00 & & \\
\hline JA-20 & 0.35 & 0.4 & 0.4 & 0.43 & 0.44 & 0.41 & 0.37 & 0.4 & 0.47 & 0.47 & 0.44 & 0.42 & 0.43 & 0.37 & 0.43 & 0.41 & 0.44 & 0.52 & 0.46 & 0.48 & 0.54 & 0.62 & 0.7 & 1.00 & \\
\hline JA-134 & 0.37 & 0.43 & 0.44 & 0.47 & 0.49 & 0.39 & 0.35 & 0.40 & 0.43 & 0.46 & 0.42 & 0.4 & 0.37 & 0.36 & 0.38 & 0.46 & 0.45 & 0.53 & 0.5 & 0.55 & 0.50 & 0.57 & 0.59 & 0.73 & 1.00 \\
\hline
\end{tabular}


The sub cluster II at 0.49 similarity coefficient is divided into Subgroup E, F, G, $\mathrm{H}$ and I. Subgroup E and $\mathrm{F}$ at 0.67 and 0.62 similarity coefficients includes 4 genotypes viz., UWS 92, UWS 77, UWS 67 and UWS 60.From these genotypes, UWS 92 and UWS 77 are related to each other whereas UWS 67 and UWS 60 are related to each other. In Subgroup $\mathrm{G}$ and $\mathrm{H}$ at 0.75 and 0.77 similarity coefficient includes 4 genotypes viz., UWS 59, UWS 56, UWS 37 and UWS 35. From these genotypes, UWS 59 and UWS 56 are related to each other and UWS 37 and UWS 35 are related to each other. The Subgroup I at 0.64 similarity coefficient includes 3 genotypes viz., UWS 32, UWS 28 and UWS 23. From these, UWS 28 and UWS 23 are related to each other.

Cluster II, a minor cluster included 5 genotypes viz., UWS 10, UWS 11, UWS 13, UWS 15 and UWS 22. It could be divided into 2 subclusters. In subcluster IV, can be divided into 2, subgroups $\mathrm{E}$ and $\mathrm{F}$.

Subgroup E has 3 genotypes viz., UWS 11, UWS 13 and UWS 15 from which UWS 11 and UWS 13 were related to each other at 0.79 similarity coefficient. Genotype UWS 22 was out grouped from first cluster as Sub cluster III having similarity coefficient value of 0.61 .

Two and three dimension principal component analysis based on RAPD data (Figs. 3 and 4, respectively) showed similar clustering of 25 genotypes as evident from cluster tree analysis. Dice similarity coefficients ranged from 0.62 to 0.78 . Most of the genotypes tended to cluster mainly into two clusters.

Cluster I major cluster including 20 genotypes and minor cluster II included 5 genotypes. Genotypes UWS 10 and UWS 22 showed maximum genetic distance and therefore the most divergent genotypes.

\section{Acknowledgements}

The authors gratefully acknowledge the financial assistance from the RKVY project "Validation of important crop varieties through DNA fingerprinting".

\section{References}

Arif, I.A., Bakir M.A., Khan, H.A., AlFarhan, A.H., AlHomaidan, A.A., Bahkali, A.H., Al Sadoon, M. and Shobrak, M. 2010. Application of RAPD for molecular characterization of plant species of medicinal value from an arid environment. Genetics and Molecular Research, 9(4):2191-2198.

Bhat, T.M., Kudesia, R. and Dar, S.A. 2012. Evaluation of Genetic Diversity among accessions of Withania somnifera (L.) Dunal using biochemical analysis and molecular markers. American-Eurasian Journal of Agriculture \& Environmental Sciences, 12(7):983-990.

CSIR. Withania somnifera L. (Dunal) (Ashwagandha).1976. In: The Wealth of India -Raw Materials. Vol. X. Council of Scientific and Industrial Research, New Delhi, India, pp 81-85.

Dharmar, K. and Britto, A.J.D. 2011. RAPD analysis of genetic variability in wild populations of Withania somnifera (L.) Dunal. International Journal of Biological Technology, 2(1):21-25.

Doyle, J.J. and Doyle, J.L. 1990. Isolation of plant DNA from fresh tissue. Focus, 12:13-15

Hoisington D, Listman GM, Morris ML. 1998. Varietal development: applied biotechnology, In ML Morris, ed, Maize Seed Industries in Developing Countries. Lynne Rienner Publishers, Inc., Boulder, pp 77-102

Khan, S and Shah, R.A. 2016. Withania somnifera (L) Dunal using RAPD and ISSR markers. Research in 
Biotechnology, 7: 01-10.

Khanna, P.K., Chandra, R., Kumar, A., Dogra, N.,Gupta, H., Gupta, G., Verma, V. 2014. Correlation between Morphological, Chemical and RAPD Markers for Assessing Genetic Diversity in Withania somnifera (L.) Dunal. Journal of Crop Science and Biotechnology, 17(1):27-34

Khatak, S., Dhillon, S., Yadav, O.P., Grewala \& Sheokand R.N. 2013. AgroMorphological and RAPD marker based characterization of genetic diversity in different genotypes of Withania somnifera L. Dunal. International Journal of Bio-Technology and Research (IJBTR), 3(4):1-16.

Mir, B.A., Koul, S., Kumar, A., Kaul, M.K, Soodan, A.S. and Raina, S.N. 2011. Assessment and characterization of genetic diversity in Withania somnifera (L.) Dunal using RAPD and AFLP markers. African Journal of Biotechnology, 10(66): 4746-4756.

Rohlf, F.J. 1993. NTSYS-pc. Numerical taxonomy and multivariate analysis system. Exeter Software, New York

Sairkar, P., Vijay, N., Batav, N., Silawat, N., Garg, R.K., Chouhan, S., Sharma, R. And Mehrotra, N.N. 2013. Genetic variability in two economically important medicinal plants of Madhya Pradesh, India and using RAPD markers Withania somnifera and Rauwolfia serpentina. Asian journal of Experimental Biological Sciences, 4(1):36-43.

Singh, S. and Kumar, S. 1998. In Withania somnifera: The Indian Ginseng,
Ashwagandha. Central Institute of Medicinal and Aromatic Plants, Lucknow, India.

Smith JSC, Smith OS. 1989. Comparison of heterosis among hybrids as a measure of relatedness with that to be expected on the basis of pedigree. Maize Genetic Cooperation Newsletter 63: 86-87

Smith JSC, Smith OS. 1992. Fingerprinting crop varieties. Adv. Agron. 47: 85-140

Stuber CW. 1995. Mapping and manipulating quantitative traits in maize. Trends Genetics. 11: 477-481.

Tiwari, P and Shrivastava A. 2016. Efficacy of RAPD markers for molecular diversity analysis of Withania somnifera (L) Dunal in central India. International journal of advanced research in biological sciences 3(7): 126-130.

Tripathi, A.K., Shukla, Y.N. and Kumar, S. 1996. Ashwagandha (Withania somnifera Dunal) (Solanaceae): a status report. Journal of Medicinal and Aromatic Plant Sciences, 18(1):46-62.

Udayakumar, R., Kasthurirengan, S., Mariashibu, T. S., Sudhakar, B. Ganapathi, A., Kim, E. J., Jang, K. M., Choi C. W. and Kim, S. C. 2013. Analysis of genetic variation among populations of Withania somnifera (L.) in South India based on RAPD markers. European Journal of Medicinal Plants, 3(2):266-280.

Williams, G. K., Kubelik, A. R., Livak, K. L., Rafalshi, J. A. and Tingey, S. V. 1990. DNA polymorphisms amplified by arbitrary primers are useful as genetic markers. Nucleic acid research, 18:6531-6535.

\section{How to cite this article:}

Surya Chauhan, Arunabh Joshi and Devendra Jain. 2017. RAPD Based Genetic Diversity Analysis in 25 Genotypes of Withania somnifera (L.) Dunal. Int.J.Curr.Microbiol.App.Sci. 6(8): 2353-2361. doi: https://doi.org/10.20546/ijcmas.2017.608.278 